\title{
AVALIAÇÃO DA TEMPERATURA NA PRODUÇÃO DE ÁCIDO LACTOBIÔNICO E SORBITOL POR CÉLULAS DE Zymomonas mobilis IMOBILIZADAS EM ALGINATO DE CÁLCIO
}

\author{
S. CARRA ${ }^{1,2}$, D.C. RODRIGUES ${ }^{1}$, N.M.C. BERALDO ${ }^{1}$, P.F. FOREST ${ }^{1}$, C. REGINATTO ${ }^{1}$, \\ V. L. BASSANI ${ }^{2}$, M. M. SILVEIRA ${ }^{1}$, E. MALVESSI ${ }^{1}$ \\ ${ }^{1}$ Universidade de Caxias do Sul, Laboratório de Bioprocessos, Caxias do Sul-RS \\ ${ }^{2}$ Universidade Federal do Rio Grande do Sul, Faculdade de Farmácia, Porto Alegre-RS \\ E-mail para contato: scarra@ucs.br
}

\begin{abstract}
RESUMO: As enzimas periplasmáticas de Zymomonas mobilis glicose-frutose oxidorredutase e gluconolactonase convertem lactose em ácido lactobiônico e frutose em sorbitol. Neste sistema, células inativadas contendo as enzimas são imobilizadas para permitir sua reutilização. As enzimas são influenciadas pela temperatura, tanto com respeito à velocidade reacional quanto à termoestabilidade. O objetivo desse estudo foi avaliar a formação de produtos sob temperaturas de $36,39,43$ e $47^{\circ} \mathrm{C}$, utilizando $20 \mathrm{~g} / \mathrm{L}$ de células imobilizadas em alginato de cálcio, com pH de 6,4 . A $43^{\circ} \mathrm{C}$, maiores concentração de produtos $(510 \mathrm{mmol} / \mathrm{L})$ e produtividade $(21,3 \mathrm{mmol} / \mathrm{L} / \mathrm{h})$ foram atingidos. A máxima velocidade específica de formação de produtos, no início do processo, foi favorecida com o aumento da temperatura devido ao maior fluxo de produtos e substratos pelas esferas de alginato. A $47^{\circ} \mathrm{C}$, entretanto, observou-se queda acentuada na velocidade, causada, possivelmente, pela desnaturação das enzimas.
\end{abstract}

\section{INTRODUÇÃO}

Glicose-frutose oxidorredutase (GFOR) e gluconolactonase (GL), enzimas presentes no periplasma da bactéria Zymomonas mobilis, têm a capacidade de converter lactose e frutose em ácido lactobiônico e sorbitol, respectivamente (Satory et al., 1997). Ácido lactobiônico apresenta importantes aplicações na área da cosmética - com função hidratante, cicatrizante e anti-radicais livres -, na área médica - como componente majoritário de soluções de conservação de órgãos a serem transplantados e vetorização de drogas - e como acidulante na indústria de alimentos (Sumimoto \& Kamada, 1990; Yu \& Van Scott, 2004; Murzina et al., 2008; Zhang et al., 2012; Chernyy et al., 2013). Sorbitol é um poliálcool utilizado como edulcorante não cariogênico na indústria de alimentos, emoliente em cosméticos e como matéria-prima básica para produção do ácido ascórbico (Birkhed et al., 1984; Budavari et al., 1996; Silveira \& Jonas, 2002; Jonas \& Silveira, 2004).

Levando em conta a preservação do meio ambiente e sustentabilidade, a obtenção por via biotecnológica de ácido lactobiônico e sorbitol vem sendo avaliada frente à síntese 
química. Para a produção desses compostos pelas enzimas GFOR/GL de Z. mobilis, diferentes técnicas e suportes para a imobilização celular têm sido empregados (Chun and Rogers, 1988, Rehr et al., 1991; Jang et al., 1992; Bertasso et al., 1996, Pedruzzi, 2010, Malvessi et al., 2010, 2013). A imobilização consiste na retenção da enzima/células em uma matriz polimérica a fim de proporcionar o aumento da concentração do catalisador no sistema reacional, maior estabilidade, facilidade na separação dos produtos, além de permitir o reaproveitamento do biocatalisador em repetidos ciclos de bioconversão. Por outro lado, devido a restrições difusionais do próprio suporte, há relatos de diminuição da velocidade reacional, que pode ser evitada ou minimizada através da escolha criteriosa de suportes e da definição de parâmetros operacionais (Zanin e Moraes, 2004).

Carra (2012) avaliou a bioprodução de ácido lactobiônico e sorbitol pelo sistema enzimático GFOR/GL de Z. mobilis imobilizado em esferas de alginato de cálcio, com respeito à massa celular imobilizada nas esferas do suporte (43, 56 e 64\% de massa celular seca por massa total da mistura). A utilização de $64 \%(\mathrm{~m} / \mathrm{m})$ possibilitou o aumento da concentração de biocatalisador na reação $(20 \mathrm{~g} / \mathrm{L})$, proporcionando a obtenção de maior produtividade. Entretanto, menor transferência de substratos e produtos através das esferas foi observada, o que poderia ter acarretado em alterações do $\mathrm{pH}$ e da temperatura no microambiente da enzima. Dessa forma, a avaliação da temperatura reacional, se faz necessária a fim de manter-se o sistema imobilizado em condições ideais de catálise.

Nesse contexto, o objetivo desse estudo foi avaliar o efeito da temperatura sobre a produção de ácido lactobiônico e sorbitol utilizando células de Z. mobilis imobilizadas em alginato de cálcio.

\section{MATERIAL E MÉTODOS}

\subsection{Produção de células/enzimas}

O microrganismo utilizado nesse estudo foi Z. mobilis ATCC 29191 (DSM 3580), adquirida do Deutsche Sammlung Von Mikroorganismen und Zellkulturen GmbH (RFA).

Neste trabalho, foi utilizado o meio líquido previamente descrito por Malvessi et al. (2006), com a seguinte composição: glicose, 20 (manutenção), 100 (inóculo), 150 (produção de células/enzimas); $\left(\mathrm{NH}_{4}\right)_{2} \mathrm{SO}_{4}, 1,0 ; \mathrm{MgSO}_{4} .7 \mathrm{H}_{2} \mathrm{O}, 0,5 ; \mathrm{KH}_{2} \mathrm{PO}_{4}, 1,0$; extrato de levedura bruto (Prodex Lac®, Prodesa S.A., Brazil), 7,5. Soluções concentradas de sais, extrato de levedura e de glicose foram preparadas separadamente, autoclavadas a 1 atm por 15 minutos e assepticamente misturadas nas devidas proporções antes da inoculação.

A ativação de culturas foi realizada adicionando-se $2 \mathrm{~mL}$ de suspensão bacteriana em estoque a um tubo contendo $18 \mathrm{~mL}$ de meio de ativação, mantidos a $30^{\circ} \mathrm{C}$ por 12 horas. Para a produção do inóculo, $45 \mathrm{~mL}$ dessa cultura foram transferidos para frascos contendo $450 \mathrm{~mL}$ de meio total, mantido sob agitação orbital de 200rpm (Certomat U/H - B. Braun Biotech, $\mathrm{RFA}$ ), a $30^{\circ} \mathrm{C}$, sob anaerobiose, por 10 horas. 
O cultivo microbiano foi realizado em regime descontínuo, em fermentador de bancada de 7,0 litros de volume total, construído na Universidade de Caxias do Sul, contendo 5,5 litros de meio. O meio de cultivo foi inoculado com o volume necessário para obter-se uma suspensão celular de 20 unidades de D.O. (densidade óptica) a $560 \mathrm{~nm}$. A temperatura do cultivo foi mantida a $30^{\circ} \mathrm{C}$ e de $\mathrm{pH}$ em 5,5 pela adição automática de $\mathrm{NaOH} 5 \mathrm{~mol} / \mathrm{L}$.

Após o término do cultivo, o caldo fermentado foi recolhido e concentrado por centrifugação, a 5836xg, por 10 minutos. A biomassa, concentrada a $25 \mathrm{~g} / \mathrm{L}$ foi, em seguida, submetida à permeabilização com $0,2 \%(\mathrm{~m} / \mathrm{v})$ de brometo de cetil trimetil amônio (CTAB), seguindo a metodologia proposta por Rehr et al. (1991) com algumas modificações.

\subsection{Imobilização celular}

Para o encapsulamento de Z. mobilis em alginato de cálcio, foi utilizada a técnica descrita por Carra (2012). Alginato de sódio Algogel 5540 (Degussa Flavors \& Fruit Systems do Brasil Ltda) foi dissolvido em água $(4 \% \mathrm{~m} / \mathrm{v})$ e mantido sob agitação por 12 horas. Paralelamente, $50 \mathrm{~g} / \mathrm{L}$ (em base seca) de células de Z. mobilis permeabilizadas foram tratadas com glutaraldeído $0,5 \%(\mathrm{~m} / \mathrm{v})$, sob agitação, por 10 minutos. Ao final desse processo, as células foram centrifugadas e ressuspensas em $70 \mathrm{~g} / \mathrm{L}$. À solução de alginato de sódio, foi adicionado igual volume de suspensão celular de Z. mobilis, sendo obtido, nesse sistema heterogêneo, $64 \%$ de massa celular seca por massa total da mistura $(\% \mathrm{~m} / \mathrm{m})$. A mistura foi novamente mantida sob agitação e, para a imobilização das células, a mistura foi lentamente gotejada em solução de $\mathrm{CaCl}_{2}$ 0,3mol/L. As esferas produzidas foram, posteriormente, reticuladas com glutaraldeído $0,5 \%(\mathrm{~m} / \mathrm{v})$ e armazenadas em água, a $4^{\circ} \mathrm{C}$. O diâmetro médio das esferas de alginato de cálcio foi de 2,36.10-3 m, determinado com o auxilio de um tamis de 6 a 16 mesh.

\subsection{Ensaios de bioconversão}

Os ensaios foram realizados com $20 \mathrm{~g} / \mathrm{L}$ de células, em reator de $600 \mathrm{~mL}$, contendo $200 \mathrm{~mL}$ de meio reacional. A solução de substratos foi preparada a partir de lactose e frutose (700+600mmol/L, respectivamente). O volume de solução de substratos foi calculado considerando a quantidade de água presente nas esferas (Carra, 2012). A condição operacional padrão de $\mathrm{pH}$ foi de 6,4 (Malvessi et al., 2006) e o processo foi conduzido sob diferentes temperaturas: $36,39,43$ e $47^{\circ} \mathrm{C}$. O reator encamisado foi acoplado a um banho termostatizado, mantido sob agitação magnética com $\mathrm{pH}$ reacional controlado pela adição automática de solução de $\mathrm{NaOH} 7,0 \mathrm{~mol} / \mathrm{L}$, contido em uma bureta de $50 \mathrm{~mL}$, através de um controlador de $\mathrm{pH}$. Os ensaios foram conduzidos pelo tempo necessário para que fosse atingido aproximadamente $70 \%$ de conversão de substratos em produtos.

\subsection{Métodos Analíticos}

A concentração celular no meio de fermentação foi determinada indiretamente pela medida da absorbância de suspensões celulares, a $560 \mathrm{~nm}$, e diretamente por gravimetria. 
Uma vez que ácido lactobiônico e sorbitol são formados em base equimolar, sendo estes os únicos produtos da reação, os substratos lactose e frutose são consumidos na mesma proporção. Sendo assim, as concentrações dos produtos formados e de substratos residuais foram estimadas indiretamente em função do volume e da concentração da solução de $\mathrm{NaOH}$ utilizada para titular o ácido formado na reação.

\section{RESULTADOS E DISCUSSÃO}

Foram avaliadas diferentes temperaturas da reação de bioconversão sobre a produção de ácido lactobiônico e sorbitol. Na Figura 1, são apresentados os perfis cinéticos de formação de produto em resposta às diferentes temperaturas de processo utilizadas e na Tabela 1 são mostrados os resultados gerais obtidos em cada condição.

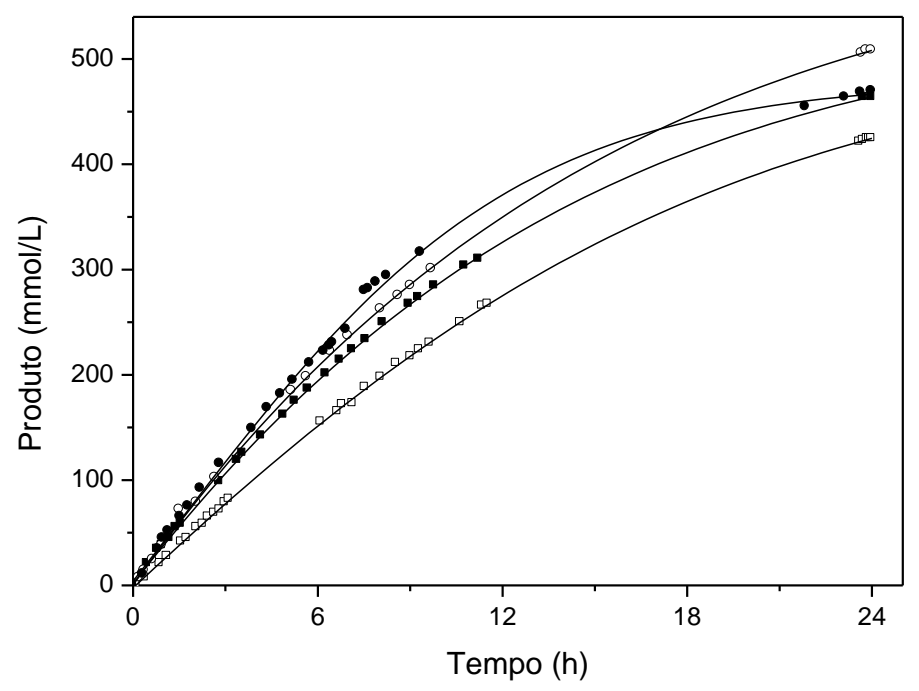

Figura 1 - Concentração de produto (ácido lactobiônico ou sorbitol) em função do tempo, em ensaios de bioconversão com células de Zymomonas mobilis utilizando 64\% de massa de células em relação à massa da mistura células + alginato de sódio, em diferentes temperaturas (Substrato inicial: lactose $700 \mathrm{mmol} / \mathrm{L}$ e frutose $600 \mathrm{mmol} / \mathrm{L}, \mathrm{pH} 6,4 ; 20 \mathrm{~g} / \mathrm{L}$ de biocatalisador).

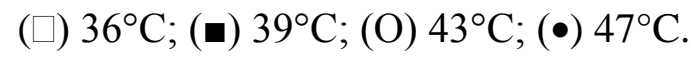

Observa-se que, em 24 horas de processo, concentrações crescentes de produto foram obtidas com o aumento da temperatura de 36 para $43^{\circ} \mathrm{C}$ (Tabela 1). Conversões em produto de 65,71 e $78 \%$ foram estimadas nos processos conduzidos a 36,39 e $43^{\circ} \mathrm{C}$, respectivamente, $\mathrm{Na}$ bioconversão realizada a $43^{\circ} \mathrm{C}$, concentração de produto de $510 \mathrm{mmol} / \mathrm{L}$ foi obtida, correspondendo a 183g/L de ácido lactobiônico e 93g/L de sorbitol. Salienta-se ainda, nesta condição a determinação de menor concentração de lactose residual, de $150 \mathrm{mmol} / \mathrm{L}$. Por outro lado, o incremento da temperatura de processo para $47^{\circ} \mathrm{C}$ resultou em queda média de $8 \%$ na produção, assim como no rendimento, quando comparado com os dados obtidos na reação realizada a $43^{\circ} \mathrm{C}$. 
Tabela 1- Resultados gerais em ensaios de bioconversão conduzidos sob diferentes temperaturas, utilizando células de Zymomonas mobilis imobilizadas em alginato de cálcio (Substrato inicial: lactose 700mmol/L e frutose 600mmol/L, pH 6,4, X=20g/L).

\begin{tabular}{|c|c|c|c|c|}
\hline \multirow{2}{*}{ Parâmetros } & \multicolumn{4}{|c|}{ Temperaturas $\left({ }^{\circ} \mathbf{C}\right)$} \\
\cline { 2 - 5 } & $\mathbf{3 6}$ & $\mathbf{3 9}$ & $\mathbf{4 3}$ & $\mathbf{4 7}$ \\
\hline $\mathrm{P}_{\max }(\mathrm{mmol} / \mathrm{L})$ & 424 & 463 & 510 & 468 \\
\hline $\mathrm{t}(\mathrm{h})$ & 24 & 24 & 24 & 24 \\
\hline$\rho(\%)$ & 65 & 71 & 78 & 72 \\
\hline $\mathrm{p}(\mathrm{mmol} / \mathrm{L} / \mathrm{h})$ & 17,6 & 19,3 & 21,3 & 19,5 \\
\hline $\mathrm{q}(\mathrm{mmol} / \mathrm{g} / \mathrm{h})$ & 0,88 & 0,96 & 1,06 & 0,81 \\
\hline$\mu_{\mathrm{P}, \max }(\mathrm{mmol} / \mathrm{g} / \mathrm{h})$ & 1,37 & 1,88 & 2,06 & 2,63 \\
\hline $\mathrm{S}_{\mathrm{f}}(\mathrm{mmol} / \mathrm{L})$ & 250 & 200 & 150 & 200 \\
\hline
\end{tabular}

$\mathrm{P}_{\max }$, concentração máxima de produto (ácido lactobiônico ou sorbitol); $\mathrm{t}$, tempo de processo; $\rho$, rendimento em produto; $p$, produtividade; $q$, produtividade específica; $\mu_{\mathrm{P}, \max }$, máxima velocidade específica de formação de produto; $\mathrm{S}_{\mathrm{f}}$, concentração de lactose residual.

Com relação à máxima velocidade específica de formação de produto $\left(\mu_{\text {Pmáx }}\right)$, determinada no início do processo, valores superiores foram obtidos com o incremento da temperatura, alcançando em $47^{\circ} \mathrm{C}, 2,63 \mathrm{mmol} / \mathrm{g} / \mathrm{h}$ (Tabela 1). Esse fato pode estar relacionado à influência positiva da temperatura na difusão de substratos e produtos através das esferas de alginato de cálcio. O incremento na temperatura induziria ao aumento do tamanho dos poros do suporte, facilitando o acesso do substrato à enzima e, como consequência, proporcionaria maior velocidade reacional. Teixeira (2011), fazendo uso de análises termogravimétricas, caracterizou o suporte de alginato de cálcio empregado na imobilização de lipases. Segundo o autor, menores temperaturas aumentam a resistência à transferência de massa, acarretando em menor difusividade de substâncias pelo suporte.

Na Figura 2, estão apresentados os perfis de velocidade específica de formação de produto $\left(\mu_{\mathrm{P}}\right)$ frente às temperaturas reacionais da bioconversão de substratos em produtos. Como a velocidade reacional do complexo GFOR/GL é influenciada pela concentração de substratos presente no meio reacional, $\mathrm{o} \mu_{\mathrm{P}}$ foi avaliado em função da concentração de lactose ao longo do processo. No início do processo, a velocidade específica de formação de produto foi favorecida com a utilização de $47^{\circ} \mathrm{C}$, entretanto, a queda foi mais acentuada em relação aos demais testes. Esse fato pode ter ocorrido em virtude da possível desnaturação da enzima. Perfis de diminuição de $\mu_{P}$ menos acentuados foram observados com a utilização de temperaturas inferiores a $47^{\circ} \mathrm{C}$.

Zachariou \& Scopes (1986) e Malvessi et al. (2013) relataram a temperatura de $39^{\circ} \mathrm{C}$ como favorável para a conversão de substratos em produtos pelo complexo enzimático GFOR/GL, com a utilização de células livres de Z. mobilis. Como pôde ser observado, em se tratando de um sistema imobilizado, o fluxo da solução de substratos e produtos tem o comportamento afetado pela barreira representada pelo suporte, em elevada concentração celular no interior das esferas. Devido a esse fato, nas condições testadas, a temperatura de 
$43^{\circ} \mathrm{C}$ proporcionou a obtenção de maior rendimento em produto e a manutenção da velocidade reacional do sistema imobilizado de Z. mobilis.

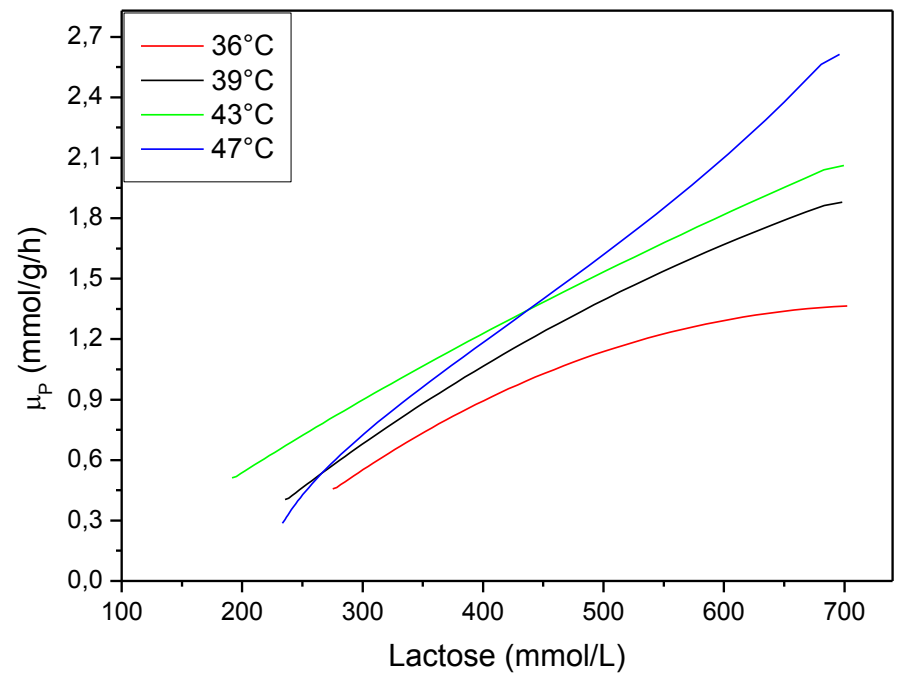

Figura 2 - Velocidade específica de formação de produto $\left(\mu_{\mathrm{P}}\right)$ em função da concentração de lactose, em ensaios de bioconversão com células de Zymomonas mobilis, utilizando 64\% de massa de células em relação à massa da mistura células + alginato de sódio, em diferentes temperaturas (Substrato inicial: lactose 700mmol/L e frutose 600mmol/L, pH 6,4; 20g/L de biocatalisador).

\section{CONCLUSÃO}

Nos testes de avaliação da temperatura no processo de bioconversão de substrato em produtos, foi identificado o incremento em termos de velocidade específica de formação de produto com o aumento da temperatura reacional. Entretanto, no decorrer do processo, a queda da velocidade foi mais acentuada com a utilização de $47^{\circ} \mathrm{C}$ em razão da menor estabilidade do complexo enzimático imobilizado em elevadas temperaturas. Nas condições avaliadas, foi constatada a temperatura de $43^{\circ} \mathrm{C}$ como favorável à condução do processo de bioconversão de lactose e frutose em ácido lactobiônico e sorbitol, respectivamente, com células imobilizadas de Z. mobilis em alginato de cálcio.

\section{AGRADECIMENTOS}

Ao apoio financeiro da UCS, UFRGS, CNPq, FAPERGS, CAPES 


\section{REFERÊNCIAS BIBLIOGRÁFICAS}

Bertasso, M., Silveira, M.M., Mancilha, I.M. Preservação da atividade da enzima glicose-frutose oxidorredutase em células imobilizadas de Zymomonas mobilis. In: XI Simpósio Nacional de Fermentações, Anais p.476, São Carlos, 1996.

Birkhed, D; Edwardsson, S.; Kalfas, S.; Svensäter, G. Cariogenicity of sorbitol. Swed Dent. J. 8(3):147-54, 1984.

Budavari, S., O`neil, M.J., Smith, A., Heckelman, P. E., Kinneary, J. F., eds. The Merck Index: an encyclopedia of chemicals, drugs, and biologicals. $12^{\text {th }}$ ed., Merck \& Co, Whitehouse Station, NJ, p.2563, 1996.

Carra S. Estudo cinético da produção de ácido lactobiônico e sorbitol por enzimas periplasmáticas de Zymomonas mobilis. Dissertação de Mestrado. Universidade de Caxias do Sul. Caxias do Sul, Brasil, 2012.

Chernyy, S,; Jensen, B. E. B.; Shimizu, K.; Ceccato, M.; Pedersen, S. U.; Zelikin, A. N.; Daasbjerg, K.; Iruthayaraj. Surface grafted glycopolymer brushes to enhance selective adhesion of HepG2 cells. Journal of Colloid and Interface Science. 404:207-214, 2013.

Chun, U.H., Rogers, P.L. The simultaneous production of sorbitol from fructose and gluconic acid from glucose using an oxidoreductase of Zymomonas mobilis. Applied Microbiology and Biotechnology. 29:19-24, 1988.

Jang, K. H., Park, C., CHUN, U. H. Improvement of oxidoreductase stability of cethyltrimethylammoniumbromide permeabilized cells of Zymomonas mobilis through glutaraldheyde crosslinking. Biotechnology Letters 14:311-316, 1992.

Jonas, R.; Silveira, M.M. Sorbitol can be produced not only chemically but also biotechnologically. Applied Microbiology and Biotechnology 118: 321-336, 2004.

Malvessi, E., Concatto, K., Carra, S.; Silveira, M.M. Formulation of medium for growth and production of ethanol and intracellular enzymes by Zymomonas mobilis. Brazilin Archives of Biology and Technology 49: 139-144, 2006.

Malvessi E.; Carra, S.; Silveira, M. M.; Ayub, M. A. Z. J. Effect of substrate concentration, pH, and temperature on the activity of the complex glucose-fructose oxidoreductase/gluconolactonase present in calcium alginate-immobilized Zymomonas mobilis cells. Biochemical Engineering Journal 51. 1$6,2010$.

Malvessi E.; Carra, S.; Pasquali, F. C.; Kern, D. B.; Silveira, M. M.; Ayub, M. A. Z. J. Production of organic acids by periplasmic enzymes presente in free and immobilized cells of Zymomonas mobilis. Journal of Industrial Microbiology Biotechnology 40:1-10, 2013.

Murzina, E.V.; Tokarev A.V.; Kordás K.; Karhu H.; Mikkola J.; Murzin, D.Y. D-Lactose oxidation over gold catalysts. Catal. Today. 131: 385-392, 2008. 
Pedruzzi I. Produção biotecnológica de sorbitol e ácido lactobiônico com separação simultânea em sistema de leito móvel simulado. Tese de doutorado. Faculdade de Engenharia. Universidade do Porto. Porto, Portugal, 2010.

Rehr, B.; Wilhem, C. Sahm, N. Production of sorbitol and gluconic acid by permeabilized cells of Zymomonas mobilis. Applied Microbiology and Biotechnology 35: 144-148, 1991.

Satory M.; Fuerling, M.; Haltrich, D.; Kulbe, K.D.; Pittner, F.; Nidetzky, B. Continuous enzymatic production of lactobionic acid using glucose-fructose oxidoreductase in an ultrafiltration membrane reactor. Biotechnology Letters 19: 1205-1208, 1997.

Scott, C.D.; Woodward, C.A.; Thompson, J.E. Solute diffusion in biocatalyst gel beads containing biocatalysis and other additives. Enzyme Microbial Technology 11:258-263, 1989.

Silveira, M.M., Jonas, R. The biotechnological production of sorbitol. Applied Microbiology and Biotecnology 59:400-408, 2002.

Sumimoto, R., Kamada, N. Lactobionate as the most important component in UW solution for liver preservation. Transplant Process 22: 2198-2199, 1990.

Teixeira, V. F. T. Estudo da obtenção de biocatalisadores com matrizes de alginato de cálcio visando a produção de biodiesel. Dissertação de Mestrado. Universidade Estadual do Norte Fluminense Darcy Ribeiro. Rio de Janeiro, Brasil, 2011.

Yu, R., Van Scott, E. Alpha-hydroxyacids and carboxylic acids. Journal of Cosmetic Dermatology 3: 76-87, 2004.

Zachariou, M., Scopes, R.K. Glucose-fructose oxidoreductase, a new enzyme isolated from Zymomonas mobilis that is responsible for sorbitol production. Journal of Bacteriology. 3: 863-869, 1986.

Zanin, G.M.; Moraes, F.F., 2004. Enzimas imobilizadas. In: Said, S. e Pietro, R.C.L.R. (Ed.) Enzimas como agentes biotecnológicos. São Paulo: Legis Summa, pp.35-85.

Zhang, M.; Eddy, C.; Deanda, K.; Finkelstein, M.; Picataggio, S. (1995) Science 267:240. In: Rogers, P.L.; Jeon Y.J., Lee, K.L., Lawford H.G. (2007). Zymomonas mobilis for fuel ethanol and Higher value products. Adv. Biochem. Engin./Biotechnol. 108: 263-288. 